\title{
Efeitos alelopáticos de extratos aquosos de um híbrido de eucalipto na germinação e vigor de sementes de alface
}

\author{
Igor Alberto Câmara da Cruz ${ }^{1}$, Emmanoella Costa Guaraná Araujo ${ }^{*}$, Tarcísio Viana de Lima ${ }^{1}$, José Antônio \\ Aleixo da Silva ${ }^{1}$, Thiago Cardoso Silva ${ }^{1}$
}

RESUMO: O trabalho analisou o potencial alelopático de extratos aquosos de folhas, frutos e casca de Eucalyptus urophylla S.T. Blake x Eucalyptus tereticornis Sm., sobre sementes de Lactuca sativa L. O experimento foi realizado sob condições higrotérmicas controladas, tendo como substrato o papel germitest ${ }^{\circledR}$ umedecido com água destilada e os extratos em concentrações de $25 \%, 50 \%, 75 \%$ e $100 \%$. Foram depositadas 25 sementes distribuídas uniformemente em caixas gerbox ${ }^{\circledR}$ com cinco repetições, em delineamento inteiramente casualizado, sendo a avaliação realizada no mesmo horário durante 10 dias. Os dados foram submetidos à análise de variância e as médias comparadas pelo teste Tukey com 5\% de erro. Foi observada a taxa de germinação (\%G), índice de velocidade de germinação (IVG), tempo médio (TM, em dias) e velocidade média (VM, em dia $\left.{ }^{-1}\right)$. O extrato aquoso de folha em todas as concentrações afetou a $\%$ G e IVG, e as concentrações 75\% e 100\% influenciaram a VM e o TM. No extrato de fruto e casca houve redução na $\% \mathrm{G}$ nas duas maiores concentrações, já o TM e VM não diferiram. O IVG não apresentou diferença significativa no extrato de casca, mas no de fruto houve influência nas concentrações de $75 \%$ e 100\%. Assim, a depender da concentração, o eucalipto apresentou potencial alelopático sobre a alface.

Palavras-chave: condições higrotérmicas, substâncias químicas, testes de germinação.

\section{Allelopathic effects of aqueous extracts of a eucalyptus hybrid on germination and vigor of lettuce seeds}

\begin{abstract}
The work analyzed the allelopathic potential of aqueous extracts from leaf, fruits and barks of Eucalyptus urophylla S.T. Blake x Eucalyptus tereticornis Sm. on seeds of Lactuca sativa L. The experiment was carried out under controlled hygrothermal conditions, having as substrate the germitest $₫$ paper moistened with distilled water and the extracts in concentrations of $25 \%, 50 \%, 75 \%$ and $100 \%$. Twenty-five seeds uniformly distributed in gerbox ${ }^{\circledR}$ boxes with five replications were deposited in a completely randomized design; the evaluation occurred at the same time for 10 days. The data were submitted to analysis of variance and the means were compared by the Tukey test with $5 \%$ error. Germination rate $(\% \mathrm{G})$, germination velocity index (GVI), mean time (MT, in days) and mean velocity $\left(\mathrm{MV}\right.$, in day $\left.^{-1}\right)$ were observed. Aqueous leaf extract at all concentrations affected $\% \mathrm{G}$ and IVG, and in the concentrations of $75 \%$ and $100 \%$ influenced MV and TM. In the fruit and bark extract, there was a reduction in the \%G in the two highest concentrations, since TM and VM did not differ. The IVG showed no significant difference in the bark extract, but in the fruit there was influence in the concentrations of $75 \%$ and $100 \%$. Thus, depending on concentration, eucalyptus presents allelopathic potential on lettuce.

Keywords: hygrothermal conditions, chemical substances, germination tests.
\end{abstract}

\section{INTRODUÇÃO}

Indivíduos do gênero Eucalyptus são amplamente cultivados pelo seu rápido crescimento e rusticidade para obtenção de madeira, celulose e extração de óleos essenciais. Com objetivo de mitigar impactos causados por plantios comerciais puros, muitas espécies têm sido plantadas em consórcio, criando um ambiente semelhante ao natural. No entanto é preciso conhecer o comportamento dos indivíduos a

Recebido em 22/08/2018; Aceito para publicação em 09/08/2019

${ }^{1}$ Universidade Federal Rural de Pernambuco

*E-mail: manuguarana@gmail.com serem integrados para verificar o processo de sinergia e antagonismo entre eles.

Um mecanismo de defesa desenvolvido pelos seres vivos, que pode apresentar características adversárias entre espécies, é a alelopatia. Neste processo, substâncias químicas produzidas no metabolismo secundário são liberadas no ambiente, por tecidos vivos ou em decomposição, interferindo na germinação, crescimento e/ou desenvolvimento de outros organismos, além de atuar contra 
herbivoria ou serem atrativos para polinizadores (PIRES; OLIVEIRA, 2001; TAIZ et al., 2017).

É indispensável compreender o processo de ação dos aleloquímicos para entenderas interações entre as plantas, sobretudo nas espécies de interesse econômico em ambiente natural ou cultivado (CRUZ-SILVA et al., 2015). Além disto, substâncias de origem vegetal também podem ser utilizadas na produção de herbicidas, auxiliando no controle de plantas daninhas (RIBEIRO et al., 2012; SILVEIRA; MAIA; COELHO, 2012b).

Tais compostos podem ser produzidos em quaisquer partes das plantas e em concentrações variadas, a depender da idade e da espécie do organismo, e sua liberação ocorre por processos como decomposição, exsudação radicular, lixiviação e volatilização (RODRIGUES; RODRIGUES; REIS, 1992; PERRY et al., 2007). A ação das fitotoxinas, em plantas receptoras, ocorre em processos como divisão e alongamento celular, fotossíntese, respiração e função estomática, permeabilidade celular e produções hormonais que fazem parte o crescimento (RICE, 1984).

Os sintomas apresentados pelas plantas alvo das substâncias podem ser inibitórios ou estimulantes, a depender do indivíduo que a produz e da espécie que sofre a ação (PELLISSIER, 2013). É extremamente importante conhecer o comportamento das espécies em comunidade para propiciar manejo adequado e melhor utilização do solo, aumentando a produtividade e a preservação ambiental.

Uma das formas mais eficazes de verificar o potencial alelopático de uma espécie é por meio de testes de germinação com aquelas que se deseja o consórcio. Porém, poucos estudos foram realizados utilizando frutos e cascas de indivíduos do gênero Eucalyptus.

Nesse sentido, o objetivo deste estudo é verificar o potencial alelopático de folhas, frutos e cascas de eucalipto, cultivados no município de Belém do São Francisco/PE, sobre a germinação de sementes e o crescimento inicial de alface.

\section{MATERIAL E MÉTODOS}

O material vegetal do híbrido Eucalyptus urophylla S. T. Blake x Eucalyptus tereticornis Sm., foi coletado no município de Belém de São Francisco - PE. O experimento foi conduzido em laboratório, utilizando extratos aquosos de cascas do fuste, frutos, e folhas, em concentrações distintas.

Como bioindicadoras foram utilizadas sementes de alface, previamente desinfetadas com hipoclorito de sódio a $2 \%$. O delineamento adotado foi inteiramente casualizado com cinco repetições e extratos com concentrações de $100 \%, 75 \%, 50 \%$ e $25 \%$, e água destilada, utilizada como controle $(0 \%)$.
Cada unidade amostral contou com 25 sementes distribuídas uniformemente.

Para a produção do extrato aquoso, pesou-se 250 g do material vegetal fresco (folhas, frutos e cascas), que foi triturado com um litro de água destilada por aproximadamente três minutos e peneirado, sendo esse extrato considerado como sendo de concentração $100 \%$. Em seguida, foram feitas as diluições, conforme as concentrações desejadas $(100 \%, 75 \%, 50 \%$ e $25 \%)$ e armazenadas em beckers.

$\mathrm{O}$ experimento foi dirigido sob condições de ambiente natural $\left(25^{\circ} \mathrm{C}\right.$ e umidade relativa de $\left.72 \%\right)$, utilizando gerbox ${ }^{\circledR}$, com dimensões de $20 \mathrm{~cm}$ x 12 $\mathrm{cm} \times 10 \mathrm{~cm}$. O substrato utilizado foi papel germitest $^{\circledR}$ previamente esterilizado em estufa de aeração forçada, a $105 \pm 5^{\circ} \mathrm{C}$, durante duas horas de acordo com as Regras Para Análises de Sementes RAS (BRASIL, 2009). O papel foi umedecido com $10 \mathrm{ml}$ de água destilada e acomodado no fundo das caixas gerbox.

As sementes foram distribuídas sobre o substrato, sendo organizadas em cinco fileiras com espaçamento uniforme e suficiente para evitar a competição e contaminação. Em seguida, pipetou-se 2,5 $\mathrm{ml}$ do extrato sobre todas as sementes de cada unidade experimental, de modo que a solução fosse distribuída homogeneamente. Como critério de germinação, adotou-se a protrusão de raiz primária de cinco milímetros (BEWLEY \& BLACK, 1994).

A coleta dos dados foi realizada diariamente, no mesmo horário, durante um período de 10 dias. Foram avaliados o percentual de germinação $(\% \mathrm{G})$, o Índice de Velocidade de Germinação (IVG), o Tempo médio de germinação (TM) e a Velocidade média de germinação (VM).

\section{RESULTADOS}

\section{Extrato aquoso de folhas}

As concentrações de extratos aquosos das folhas de eucalipto interferiram significativamente na porcentagem de germinação e índice de velocidade de germinação quando comparados com o controle (Tabela 1). 
Tabela 1: Porcentagem, índice de velocidade de germinação (IVG), tempo médio (dias) e velocidade média (dia ${ }^{-1}$ ) de germinação das sementes de Lactuca sativa L. submetidas a diferentes concentrações de extrato aquoso de folhas de Eucalyptus urophylla $\mathrm{x}$ Eucalyptus tereticornis.

\begin{tabular}{ccccc}
\hline $\begin{array}{c}\text { Concentração do extrato aquoso } \\
(\mathbf{\%})\end{array}$ & $\begin{array}{c}\text { Germinação } \\
(\mathbf{\%})\end{array}$ & $\mathbf{I V G}$ & $\begin{array}{c}\text { Tempo médio } \\
\text { (dias) }\end{array}$ & $\begin{array}{c}\text { Velocidade média } \\
\left.\mathbf{( d i a}^{-1}\right)\end{array}$ \\
\hline $\mathbf{0}$ & $76,8 \mathrm{a}$ & $7,41 \mathrm{a}$ & $3,31 \mathrm{~b}$ & $0,30 \mathrm{ab}$ \\
$\mathbf{2 5}$ & $58,4 \mathrm{~b}$ & $5,58 \mathrm{~b}$ & $3,27 \mathrm{~b}$ & $0,31 \mathrm{a}$ \\
$\mathbf{5 0}$ & $39,2 \mathrm{c}$ & $2,75 \mathrm{c}$ & $4,83 \mathrm{ab}$ & $0,22 \mathrm{bc}$ \\
$\mathbf{7 5}$ & $40,0 \mathrm{c}$ & $2,62 \mathrm{c}$ & $5,57 \mathrm{a}$ & $0,19 \mathrm{c}$ \\
$\mathbf{1 0 0}$ & $29,6 \mathrm{c}$ & $1,79 \mathrm{c}$ & $5,79 \mathrm{a}$ & $0,18 \mathrm{c}$ \\
\hline $\mathbf{C V}(\boldsymbol{\%})$ & 18,10 & 17,97 & 22,00 & 20,10 \\
\hline
\end{tabular}

Médias seguidas de letras iguais nas colunas não diferem entre si significativamente pelo teste de Tukey no nível de 5\% de probabilidade. $\mathrm{CV}=$ Coeficiente de variação

É possível verificar que, com o aumento da concentração do extrato, o percentual de germinação é reduzido, sendo a menor média encontrada na concentração de $100 \%$. Os tratamentos com $50 \%$, $75 \%$ e $100 \%$ do extrato não diferiram estatisticamente entre si, no entanto diferiram do controle e da concentração $25 \%$.

$\mathrm{O}$ índice de velocidade de germinação apresentou diferença significativa entre todos os tratamentos ao ser comparado com a testemunha. A maior diferença ocorreu entre a testemunha e a concentração $100 \%$. Enquanto os tratamentos com 50\%, $75 \%$ e $100 \%$ do extrato, assim como no percentual de germinação, não diferiram significativamente.

O tempo médio de germinação variou entre 3,31 e 5,79 dias, sendo que os tratamentos de $50 \%, 75 \%$ e
$100 \%$ não diferiram estatisticamente entre si, assim como os tratamentos de $50 \%$ e $25 \%$. Na velocidade média de germinação a variação foi de $0,18(100 \%)$ a $0,31(25 \%)$. Houve diferença significativa entre a velocidade média da testemunha e dos tratamentos com $75 \%$ e $100 \%$ do extrato.

\section{Extrato aquoso de frutos}

As concentrações de $75 \%$ e $100 \%$ do extrato aquoso de frutos eucalipto interferiram na porcentagem de germinação e no índice de velocidade de germinação das sementes de alface, enquanto as concentrações de $25 \%$ e $50 \%$ não diferiram da média obtida pela testemunha (Tabela 2).

Tabela 2: Porcentagem, índice de velocidade de germinação (IVG), tempo médio (dias) e velocidade média (dia ${ }^{-1}$ ) de germinação das sementes de Lactuca sativa L. submetidas a diferentes concentrações de extrato aquoso de fruto de Eucalyptus urophylla x Eucalyptus tereticornis.

\begin{tabular}{cclcc}
\hline $\begin{array}{c}\text { Concentração do extrato } \\
\text { aquoso }(\boldsymbol{\%})\end{array}$ & $\begin{array}{c}\text { Germinação } \\
\mathbf{( \% )}\end{array}$ & IVG & $\begin{array}{c}\text { Tempo médio } \\
\text { (dias) }\end{array}$ & $\begin{array}{c}\text { Velocidade média } \\
\left.\mathbf{( d i a}^{-\mathbf{1}}\right)\end{array}$ \\
\hline $\mathbf{0}$ & $76,8 \mathrm{a}$ & $7,41 \mathrm{a}$ & $3,31 \mathrm{a}$ & $0,30 \mathrm{a}$ \\
$\mathbf{2 5}$ & $69,6 \mathrm{ab}$ & $6,53 \mathrm{ab}$ & $3,32 \mathrm{a}$ & $0,30 \mathrm{a}$ \\
$\mathbf{5 0}$ & $75,2 \mathrm{a}$ & $6,63 \mathrm{ab}$ & $3,78 \mathrm{a}$ & $0,27 \mathrm{a}$ \\
$\mathbf{7 5}$ & $51,2 \mathrm{c}$ & $4,49 \mathrm{c}$ & $4,00 \mathrm{a}$ & $0,26 \mathrm{a}$ \\
$\mathbf{1 0 0}$ & $55,2 \mathrm{bc}$ & $4,90 \mathrm{bc}$ & $4,15 \mathrm{a}$ & $0,25 \mathrm{a}$ \\
\hline $\mathbf{C V}(\boldsymbol{\%})$ & 12,53 & 15,25 & 17,36 & 14,97 \\
\hline
\end{tabular}

Médias seguidas de letras iguais nas colunas não diferem entre si significativamente pelo teste de Tukey no nível de 5\% de probabilidade.

$\mathrm{CV}=$ Coeficiente de variação

No entanto, o tempo médio e a velocidade média não apresentaram diferença significativa quando comparados com a testemunha, indicando assim que não existe influência dos extratos em qualquer das concentrações nas duas variáveis.

Extrato aquoso de casca

Analisando os parâmetros do processo de germinação da alface sobre a presença do extrato aquoso de casca de eucalipto, observou-se diferença significativa na percentagem de sementes germinadas entre a testemunha e os tratamentos $75 \%$ e $100 \%$ (Tabela 3). 
Tabela 3: Porcentagem, índice de velocidade de germinação (IVG), tempo médio (dias) e velocidade média (dia ${ }^{-1}$ ) de germinação das sementes de Lactuca sativa L. submetidas a diferentes concentrações de extrato aquoso de casca de Eucalyptus urophylla $\mathrm{x}$ Eucalyptus tereticornis.

\begin{tabular}{ccccc}
\hline $\begin{array}{c}\text { Concentração do extrato aquoso } \\
(\%)\end{array}$ & $\begin{array}{c}\text { Germinação } \\
(\mathbf{\%})\end{array}$ & IVG & $\begin{array}{c}\text { Tempo médio } \\
\text { (dias) }\end{array}$ & $\begin{array}{c}\text { Velocidade média } \\
\left(\mathbf{d i a}^{-\mathbf{1}}\right)\end{array}$ \\
\hline $\mathbf{0}$ & $76,8 \mathrm{a}$ & $7,41 \mathrm{a}$ & $3,31 \mathrm{a}$ & $0,30 \mathrm{a}$ \\
$\mathbf{2 5}$ & $74,4 \mathrm{ab}$ & $7,54 \mathrm{a}$ & $3,10 \mathrm{a}$ & $0,33 \mathrm{a}$ \\
$\mathbf{5 0}$ & $68,0 \mathrm{abc}$ & $6,82 \mathrm{a}$ & $3,22 \mathrm{a}$ & $0,33 \mathrm{a}$ \\
$\mathbf{7 5}$ & $64,0 \mathrm{bc}$ & $6,46 \mathrm{a}$ & $3,42 \mathrm{a}$ & $0,31 \mathrm{a}$ \\
$\mathbf{1 0 0}$ & $56,0 \mathrm{c}$ & $5,42 \mathrm{a}$ & $3,45 \mathrm{a}$ & $0,30 \mathrm{a}$ \\
\hline $\mathbf{C V}(\mathbf{\%})$ & 9,69 & 16,94 & 21,15 & 20,77 \\
\hline
\end{tabular}

Médias seguidas de letras iguais nas colunas não diferem entre si significativamente pelo teste de Tukey no nível de 5\% de probabilidade.

$\mathrm{CV}=$ Coeficiente de variação

Os tratamentos e a testemunha nas variáveis, índice de velocidade de germinação, tempo médio e velocidade média não apresentaram diferença estatística.

\section{DISCUSSÃO}

Extrato aquoso de folhas

Em trabalhos realizados com extratos de folhas de Corymbia citriodora (Hook.) K.D. Hill \& L.A.S. Johnson, Ferreira et al. (2013) verificaram que diferentes concentrações não apresentaram efeitos inibitórios na percentagem de germinação ou no índice de velocidade de germinação de sementes de alface, diferindo dos resultados do híbrido utilizado neste estudo.

Souza e Cardoso (2013) concluíram que as folhas de Eucalyptus grandis W. Hill E x Maiden nas concentrações de $50 \%, 75 \%$ e $100 \%$ causaram inibição no processo germinativo de sementes de alface. No entanto, em extratos aquosos de $E$. grandis com sementes de feijão (Phaseolus vulgaris L.) não houve interferência, quando comparado com o controle.

Ferraz et al. (2014) não observaram efeito alelopático no uso de extratos de folhas de eucalipto (Corymbia citriodora (Hook.) K.D. Hill \& L.A.S. Johnson) na germinação de sementes de tomate cv. Super Marmande. No entanto, o mesmo estudo observou que os extratos afetaram o percentual de germinação de cebola (Allium cepa L.) cv. Crioula.

\section{Extrato aquoso de fruto}

Estudo realizado por Lima et al. (2015) detectou que extratos aquosos de frutos de Piper aduncum L. possuem efeito alelopático sobre o IVG de sementes de cebola, pois com o aumento da concentração do extrato houve diminuição do índice de velocidade de germinação das sementes. Segundo Ferreira e Aquila (2000), o efeito alelopático não é observado apenas na porcentagem de germinação, mas também no
IVG, comprovando assim a atividade alelopática constatada por Lima et al. (2015).

Lima et al. (2016) realizaram teste de germinação e desenvolvimento de plântulas de trigo (Triticum aestivum L.) e azevém (Lilium multiforum Lam.) com extratos de frutos de crambe (Crambe abyssinica Hochst), onde observaram que houve influência alelopática positiva na germinação do trigo em comparação com a de azevém. No entanto, conforme as concentrações aumentavam, observaram diminuição do índice de velocidade de germinação para ambas as culturas.

Nicolini et al. (2012) notaram que extratos aquosos de frutos de Passiflora edulis Sims, nas concentrações de $50 \%$ e $100 \%$, apresentam atividade alelopática negativa na germinação de alface e no crescimento de raiz, reduzindo assim os valores em comparação a testemunha e ao tratamento com $25 \%$ de concentração do extrato.

\section{Extrato aquoso de casca}

Cascas de eucalipto influenciaram na germinação de sementes de alface ao borrifar extrato aquoso como um dos tratamentos em testes de germinação (SILVEIRA, 2011). A diferença para a testemunha, borrifada com água, foi significativa. No entanto, foi observada maior influência do extrato aquoso de folhas em relação ao extrato da casca.

Fernandes et al. (2014), ao utilizarem extratos etanólicos e aquosos de cascas de Pouteria ramiflora (Mart.) Radlk, constataram que não houve efeito significativo na germinação de alface. No entanto, verificaram que o crescimento das plântulas foi reduzido, indicando possível efeito alelopático. Assim, os resultados obtidos por esses autores divergiram dos observados no presente estudo com extratos aquosos de casca de eucalipto, onde se constatou efeito na germinação de alface.

Ainda segundo os autores que avaliaram o potencial alelopático de galhos de $P$. ramiflora na germinação de sementes de alface e tomate, os extratos aquosos apresentaram efeito alelopático na 
cultura do tomate, interferindo na percentagem de germinação, tempo médio de germinação e o índice de velocidade de germinação.

Silveira et al. (2012a) estudaram o potencial alelopático da casca de jurema-preta (Mimosa tenuiflora (Willd.) Poir.) na germinação de sementes e crescimento de plântulas de alface. Eles observaram que a porcentagem de germinação e o índice de velocidade de germinação não tiveram diferença significativa entre os extratos e a testemunha. No entanto, as altas concentrações de extrato aquoso afetaram o desenvolvimento das plântulas, destacando-se os danos drásticos no comprimento da raiz e da parte aérea.

\section{CONCLUSÃO}

Extratos de folhas, frutos e cascas de Eucalyptus urophylla $\mathrm{x}$ Eucalyptus tereticornis exerceram influências no comportamento germinativo de sementes de alface, sobretudo nas concentrações mais elevadas, sendo necessários novos estudos com outras espécies com as quais se deseja consórcio.

\section{REFERÊNCIAS}

BEWLEY, J. D.; BLACK, M. Seeds: physiology of development and germination. New York: Plenum Press, 1994. 445p.

BRASIL. Ministério da Agricultura, Pecuária e Abastecimento. Regras para análise de sementes. Brasília: Mapa/ACS, 2009. 399p.

CRUZ-SILVA, C. T. A.; NASU, E. G. C.; PACHECO, F. P.; NOBREGA, L. H. P. Allelopathy of Bidens sulphurea L. aqueous extracts on lettuce development. Revista Brasileira de Plantas Medicinais, v. 17, n. 41, p.679684, 2015.

FERNANDES, R. M.; OLIVEIRA, A. K. M.; ABREU, C. A. A.; SILVA, B. C. F. L. Ação alelopática dos galhos de Pouteria ramiflora (mart.) Radlke na germinação de Lactuca sativa (alface) e Lycopersicon esculentum (tomate). Cadernos de Agroecologia, Dourados-MS, v.9, n.4, p. 000-000, 2014.

FERREIRA, A. G.; AQUILA, M. E. A. Alelopatia: uma área emergente da ecofisiologia. Revista Brasileira de Fisiologia Vegetal, Londrina, v.12, n. 0, p.175-204, 2000.

FERREIRA, D. A. T.; SILVA, M. S. A.; MONTEIRO, E. C.; DUARTE, J. A. S.; SILVA, L. D.; CABANEZ, P. A. Efeito alelopático do extrato aquoso de Eucalyptus citriodora na germinação de sementes de Lactuca sativa. In: I Seminário de biodiversidade de Agrossistemas Amazônicos, Alta Floresta - MT, 2013.

FERRAZ, A. P. F.; PINTO, M. A. D. S. C.; COELHO JÚNIOR, L. F.; CALADO, T. B.; ARAÚJO, A. V.
Potencial alelopático do extrato aquoso de folhas de eucalipto na germinação e no crescimento inicial da cebola e do tomateiro. Enciclopédia Biosfera, Centro Científico Conhecer - Goiânia, v. 10, n.19, p. 000-000, 2014.

LIMA, S. J.; ROCHA, V. D.; ROSSI, A. A. B.; SILVEIRA, G. F.; ROCHA, V. L. P. atividade alelopática de extratos do fruto de Piper aduncum 1. na germinação e crescimento inicial de cebola.In: III Seminário de Biodiversidade e Agroecossitemas Amazônicos, Cáceres - MT, v.2, n.1, 2015.

LIMA, C. T.; SIMONETTI, A. P. M. M.; MONTIEL, C. B. Extrato de frutos de crambe sobre a germinação e desenvolvimento inicial de plântulas de trigo e azevém. Acta Tecnológica, v.11, n.1, p. 000-000, 2016.

NICOLINI, J. T.; BIDO, G. S.; ZONETTI, C. P. Efeito do Extrato Aquoso de Passiflora edulis Sims Sobre a Germinação e Crescimento Inicial de Alface. Revista em Agronegócios e Meio Ambiente, v.5, n.1, p. 000-000, jan./abr. 2012.

PELLISSIER, F. Improved germination bioassays for allelopathy research. Acta Physiologia e Plantarum, v.35, n. 0, p. 23-30, 2013.

PERRY, L. G., THELEN, G. C., RIDENOUR, W. M., CALLAWAY, R. M., PASCHKE, M. W.; VIVANCO, J. M. Concentrations of the allele chemical $( \pm)$ - catechin in Centaurea maculosa soils. Journal Chemical Ecology, v. 33, n. 0, p. 337-344, 2007.

PIRES, N. M.; OLIVEIRA, V. R. Alelopatia. In: OLIVEIRA JR., R. S.; CONSTANTIN, J. (Coord.). Plantas daninhas e seu manejo. Guaíba: Ed. Agropecuária. 2001. p. 145-185.

RIBEIRO, L. O.; BARBOSA, S.; BALIEIRO, F. P.; BEIJO, L. A.; SANTOS, B. R.; GOUVEA, C. M. C. P.; PAIVA, L. V. Fitotoxicidade de extratos foliares de barbatimão [Stryphnodendron adstringes (Mart.) Coville] em bioensaio com alface. Revista Brasileira de Biociências, Porto Alegre, v. 10, n. 2, p. 220-225. 2012.

RICE, E. L. Allelopathy. 2. ed. New York: Academic, 1984. $422 \mathrm{p}$.

RODRIGUES, L. R. A.; RODRIGUES, T. J. D.; REIS, R. A. Alelopatia em plantas forrageiras. Jaboticabal: UNESP/FUNEP, 1992. 18 p. Boletim.

SILVEIRA, L. G. Ação dos aleloquímicos presentes no eucalipto e sua influência no plantio de alface. Fundação Educacional do Município de Assis (FEMA), Assis, 2011.

SILVEIRA, P. F.; MAIA, S. S. S.; COELHO, M. F. B. P. Potencial alelopático do extrato aquoso de cascas de jurema preta no desenvolvimento inicial de alface. 
Revista Caatinga, Mossoró, v.25, n.1, p. 000-000, jan./mar. 2012a.

SILVEIRA, P. F.; MAIA, S. S. S.; COELHO, M. F. B. Potencial alelopático do extrato aquoso de folhas de Mimosa tenuiflora (Willd.) Poir. na germinação de Lactuca sativa L. Bioscience Journal, Uberlândia, v. 28, n. 3, p. 472-477, 2012 b.
SOUZA, V. M.; CARDOSO, S. B. Efeito alelopático do extrato de folhas de Eucalyptus grandis sobre a germinação de Lactuca sativa L. (alface) e Phaseolus vulgaris L. (feijão). Revista Eletrônica de Educação e Ciência (REEC), v. 3, n. 2, p. 000-000, 2013.

TAIZ, L.; ZEIGER, E.; MOLLER, I. M.; MURPHY, A. Fisiologia e desenvolvimento vegetal. 6. ed. Porto Alegre: Artmed, 2017. 858p. 